\title{
An evaluation of the competencies of teachers of gifted \&talented students of professional practice adopted by the council for exceptional children (CEC) in Jordan
}

\author{
Amani Mahmoud \\ Special Education Dept. Middle East University (MEU),Amman-Jordan \\ Email address: \\ amanimahmoud2006@gmail.com,amahmoud@meu.edu.jo
}

To cite this article:

Amani Mahmoud. An Evaluation of the Competencies of Teachers of Gifted \& Talented Students of Professional Practice Adopted By the Council for Exceptional Children (CEC) in Jordan. Science Journal of Education. Vol. 1, No. 1, 2013, pp. 12-19.

doi: $10.11648 /$ j.sjedu.20130101.13

\begin{abstract}
This study aims at: Identifying the degree to which the teachers of gifted/ talented students (G/T teachers') possess the skills and knowledge approved by the Council for Exceptional Children (CEC). The study instruments were administered among the teachers of pioneer centers for gifted students; in addition to the teachers of resource rooms in the different governorates across Jordan. The study population consisted of (220) male and female teachers; whereas the study sample included only (100) male and female teachers operating in both the private and governmental schools and pioneer centers in all governorates of Jordan. The results of the study question indicate that the teachers enjoy a high degree of the concerned standards on the scale as a whole (the overall degree). The researcher pointed out in this study to the importance of taking care of the assessment and evaluation issues concerning the G/ T teachers; besides creating and developing specific measures that are especially designated to assess the competencies of the other categories' teachers within the private education field.
\end{abstract}

Keywords: Competencies, Gifted\& Talented, Council for Exceptional Children

\section{Introduction}

There are many published papers on preparing, qualifying and training the $\mathrm{G} / \mathrm{T}$ teachers of talented students all over the world [10] [20] [6] . This research is to shed the light upon the degree to which the G/T students male and female teachers possess the skills and knowledge associated with teaching G/T students and evaluating the competencies of their teachers under the professional practice approved by the Council for Exceptional Children in Jordan. By reviewing several literature studies on the same subject-matter, we find out that the first part and most of them deal with the degree to which the G/T teachers demonstrate the necessary competencies for them. These studies indicate that the most important competency for the mentioned teachers is being informed on the G/T students needs, having the skills to improve the superior power of thinking and being able to develop creative problemsolving techniques, improve the curricula modules of the G/T students and enhance their ability to conduct independent research papers [5] [9] [16] investigated the compe- tencies the G/T student teachers should have and found out that the teachers who show high efficiency in dealing with the G/T students prefer the educational axes and abstract concepts and they are characterized by their openmindedness and flexibility. The study results also revealed that the teacher's characteristics and the intellectual approach may play a significant role in the degree to which the teacher operates efficiently when dealing with G/T students. It was also found out that the teacher occupies the first place when it comes to the importance of the success of the G/T students training programs among another (15) main factors identified by the experts operating in teaching the $\mathrm{G} / \mathrm{T}$ students field; the curricula came second and the financial resources came in the $10^{\text {th }}$ place on the same list [19]. Both [14] focused on the necessity that the teachers of the gifted students should have sufficient knowledge and training. They noted that the lack of knowledge among usual classrooms teachers indicates the lack of knowledge aspects among the teachers of gifted students, in addition to that they did not make except very simple modification, on gifted curricula. The study of [4] aimed at investigating the characteristics and competencies of gifted students teachers 
as perceived by Hong Kong students. In this study, fifty teachers estimated the importance of (25) characteristics or feature, and (14) competency of characteristics and competencies of gifted students' teachers. The classified characteristics are considered to be ideal are the most important. The most important findings of this study is necessity of not ignoring the development of psychological, professional and personal characteristics that lead to find the effective teaching in the programs of teachers' preparation. Paryman and Mosha (1990) [18] investigated the need of the regular class teacher for gifted teaching. The study sample composed of (44) teachers who teach the age classes (kindergarten-12 year).The study teachers were subjected to a training program to teach gifted students. Data were collected through questionnaire, before the end and during the training program. Teachers were asked to observe competencies according to their needs. The study findings revealed that the evaluation of the curriculum ,behavioral strategies and design of means of evaluation are the most important competencies which sample subjects need to teach the gifted students. Silverman ,1980 compared between teachers who are experts in gifted students, and regular students' teachers. The study found that the expert teachers enjoy the following: they give less amount of information, and create more positions that call for thinking and learning of students, and ask more questions of differentiated thinking, and demonstrate less tendency to make judgments and criticism, and encourage students to evaluate their works and expend more time with the students. The finding of [12] study was that the trained teachers for teaching gifted and talented student are more capable to develop a positive classroom environment compared with the untrained teachers. The researcher found that the variables which had significant difference are: independence consolidation, using teaching aids, supply students with various experiences, develop creation, develop plans to achieve goals and ensure the use of higher-order thinking skills. Donia and Micheal (2004) [7] investigated the characteristics and competences of gifted students' teachers of multi-cultures. The findings of this study implied that the availability of competences such as: flexibilities and multicultural knowledge help the teacher deal with students positively. The study stressed the necessity of focusing on the competences of the gifted teacher, giving him the skills required to direct students' behavior and abilities effectively, and develop training programs in cultural and lingual aspects for the teachers which help them to perform their work effectively. Shaunessy (2005) [21], evaluated and address the teachers' attitudes toward the technology of using information technology (IT) in the classes of gifted students from kindergarten up to the twelfth grade. The findings of the study relieved that the National Association for Gifted Children (NAGC) has developed new criteria that emphasize the role of IT technique in gifted programs as technical criteria for the programs of gifted students. The study stressed the importance of using the new criteria developed by the national association of the gifted students (NAGC) by both Landrum, Callahan \&Shaklee [15]. The new criteria recommended the importance of using IT as tools to teach the gifted students, and it should be available for gifted students. Further, the study denoted that no research was issued related to teachers' stands towards using the technique of IT in the gifted programs.

Studies that were conducted about the impact of personal characteristics of teachers on scientific achievement levels show that gifted students who face some school and home difficulties are able to improve fast when they are cared about teachers who are able to provide them with the feeling of responsibility. In addition, there is a strong correlation between the efficiency of education and teachers' emotional characteristics that exceeds the correlation between these characteristics and the cognitive characteristics of the teachers, and teachers who are stable, warm, kind and tolerant toward attitudes and motives of their students, and express kind feelings toward them, accept their thoughts and encourage them to contribute in various classroom activities those teachers are more effective than others [11]. In addition to what was indicated in the study of Newland (1962) as he stressed on the importance of the availability of scientific intelligence of the gifted students as he identified it by the percentage of (120)for the teachers of gifted students in the elementary stage, and (130) for the teachers of high school (secondary stage)on Wechsler scale for adults intelligence in the verbal part. Amois,\&Shalkee (1983) [1] in their study the desired competences in teaching the gifted students in Britain. The study sample was composed of (96) teachers. They were asked to classify the competences already available and those to be reached. The findings of this study revealed three points of significant difference between the already available competences and those to be reached, they are: methods and means of evaluation, curriculum development, and personal skills to strengthen self-esteem. Both Carrington, \& Baily (2000) [3] conducted a study to investigate the opinion of pre-service teachers towards the gifted students. The study concluded that teachers in the pre-service period possess a positive opinion compared with in- service teachers .The study recommended the necessity of training pre-service teachers along with training courses during service for teachers to be adopted to deal with gifted students. Easterl (2001) [8] found that there is a need to develop programs specific of gifted students, and there is a lack in teachers specialized in gifted teaching. Curricula freezing and the lack in the special enriching programs, and need for multi-criteria and tools required to uncover the gifted. In term of Arabic research literature that addressed the field of competences of gifted teachers, the researcher of this study found a lack in this domain, so there is still a need to conduct more studies about the competences of gifted students' teachers.

Gifted and talented students' core movement has notably developed in Arab world so that G/T students' care has become a necessity to rope with massive developments in 
the world wide. Since this category represents a national wealth, services and programs that fit their capabilities should be provided. Talented and gifted care movement witnessed an increasing interest in many of the world s' countries including Arab countries in the past decades. Several scientific international and national societies were established that contributed so much in caring about this category to move forward through various conferences, seminars and scientific meetings in addition to conducting studies and scientific research .The Hashemite Kingdom of Jordan coped with this development because of its importance for this category and the whole country, in general .

Jordan was the first of the Arab countries which cared about $\mathrm{G} / \mathrm{T}$ students in a unique manner through both private and public sectors. Minister of Education took the responsibility to care about $\mathrm{G} / \mathrm{T}$ students as it established a special division in educational directorate that is responsible in the following up G/T students in Jordan in 1995.This dept is responsible for pursuing G/T students' programs, prepare and train the instructors, as well.

The interest of the ministry of education in this issue comes to cope with quantitative and qualitative development in programs and services provided to this category of students that complies with provisions and regulations stipulated in the law of ministry of education in paragraphs (A\&B) of article (41) of ministry of education law No.3 of 1993 and its amendments, as well as the provision of Disabled Rights Law No.31 of 2007 that illustrates the role of the ministry in this concern and emphasizes to innovate programs for disabled students, and G/T students ,as well. In addition, it complies with what is provided in the national strategy of Disabled issued in feb,2007 in accordance with the Royal Decree that calls to develop a department for special education based on tasks, programs, services and burdens that necessitate coping with this development, in addition to the increased number of students with special needs in all stages of education. The needs of such students shall be satisfied through specialized educational programs that cover all of their categories, and implement them through specialized competent departments.

Caring of G/T students progressed on the level of universities which innovated specializations in the filed of (G/T ) in the graduate studies. Also the universities supply courses of gifted education on Diploma and bachelor degree level. There are several studies and research related to gifted and talented that were conducted in the universities of Jordan.

Ministry of education ,through the division of gifted students programs, implemented several programs that care of G/T students. These programs include the following: The Academic Acceleration Program; The Program of resource rooms for the G/T students; The Program of King Abdullah the $2^{\text {nd }}$ schools for Excellence; The program of the leading centers for the G/T students. Ministry of education, in 1996, started to establish three leading centers that care about $\mathrm{G} / \mathrm{T}$ students through providing enriching programs to them in the basic materials, and the services of using Information Technology (IT), and introduction of computers in teaching students, in addition to providing specialized courses in various activities, such as music and languages.

In continuation of developing and expanding such services, the ministry established other leading centers in the different areas of Jordan. The number of these centers reached (17) at the beginning of the school year 2007-2008

The ministry seeks to generalize the idea of such leading centers in all directorate with in the plan of ministry of education in expanding G/T students programs of 20082012. The program of King Abdullah the $2^{\text {nd }}$ schools for Excellence has set Criteria to appoint gifted and talented instructors in these schools provided that they shall be specialized in the filed of $\mathrm{G} / \mathrm{T}$ students with master or bachelor degree [13].

In this study, we referred to the professional practice standards approved by the Council for Exceptional Children which included (5) dimensions. Some dimensions' paragraphs in the said standards were altered to go along with the Jordanian culture. These dimensions are as follows: ("Foundations", " Development \&Learners' Characteristics", "Individual Learning Differences", "Instructional Strategies", "Assessment".

\section{Purpose of Study}

This study aims at assessing the competencies of the G/T students teachers in light of the professional practice approved by the Council for Exceptional Children in Jordan.

\subsection{Research Question}

This study is to answer the following question:

To which degree do the G/T teachers possess the skills and knowledge approved by the (CEC)?

\subsection{Method}

The questionnaire was used as a research instrument to verify the research problem in this study. The questionnaire included the professional practice standards approved by the(CEC) after being translated. The authenticity and stability indications were then deduced and formulated in the form of a scale assessing the degree to which the G/T teachers in Jordan meet these standards.

\subsection{Participants}

The study participants were randomly selected from the male and female teachers operating in the resource rooms and both the governmental and private schools for $\mathrm{G} / \mathrm{T}$ students. (100) male and female teachers were selected from the study population which consists of (250) male and female G/T teachers distributed among the different governorates in the HKJ (from North to South). 


\subsection{Study Instrument}

For the purposes of this study, the researcher developed a scale based on the professional practice standards approved by the (CEC). The scale consisted of (5) dimensions; some dimensions' paragraphs were altered; so that they suit the Jordanian culture; as follows: (the $1^{\text {st }}$ dimension " Foundations " consisted of 11 paragraphs, the $2^{\text {nd }}$ dimension " Development \&Learners' Characteristics " consisted of 5 paragraphs, the $3^{\text {rd }}$ dimension "Individual Learning Differences" consisted of 6 paragraphs, the $4^{\text {th }}$ dimension " Instructional Strategies" consisted of 8 paragraphs, the $5^{\text {th }}$ dimension " Assessment " consisted of 7 paragraphs.

Table (1) Stability Coefficients for Study Instrument \& its Fields

\begin{tabular}{llc}
\hline No. & Standards & Cronbach-Alpha \\
\hline 1 & Foundations & 0.94 \\
2 & Developmental \&Characteristics of Learners & 0.88 \\
3 & Individual Learning Differences & 0.87 \\
4 & Instructional Strategies & 0.92 \\
5 & Assessment & 0.96 \\
& Total Score & 0.98 \\
\hline
\end{tabular}

In order to verify the stability of the study instrument using the internal consistency method, Cronbach's Alpha coefficient was used to test the degree of consistency in the respondents' answers to the questionnaire's questions. It was found out that the stability coefficients for the questionnaire's fields were fairly good and acceptable for the study purposes; as the values of Cronbach's Alpha coeffi- cient are as illustrated in table (1) below:

\subsection{Procedure}

The researcher contacted the Ministry of Education, the $\mathrm{G} / \mathrm{T}$ section, and cooperated with them in administering the questionnaire among the male and female teachers of the pioneer centers and the $\mathrm{G} / \mathrm{T}$ resource rooms in the Kingdom $(n=250)$; only (100) male and female teachers responded. The degree to which the G/T students teachers possess the skills and knowledge approved by the Council for Exceptional Children was divided into (3) levels; as follows: high if the mean average ranges between (1-1.67), moderate if the mean average ranges between (1.68- 2.35) $\&$ low if the mean average ranges between (2.36- 3.00). The division was as follows: there are (3) alternatives in the questionnaire $(3-1)=2 / 3=0.67$

\subsection{Data Analysis}

Several statistical approaches were used to analyze the study data; including the mean averages, SD's, variance analysis for the differences.

\subsection{Results}

First: the results concerning the first question, "to which degree do the G/T teachers possess the skills and knowledge approved by the (CEC)?" In order to answer the first question, the mean average and SD values were calculated; the rank and degree of possession according to the questionnaire's dimensions were also identified; as follows:

Table (2) The mean averages, SD's, rank and degree to which the G/ T teachers possess the concerned skills and knowledge according to the paragraphs of the "Foundations" dimension are here in identified in descending order

\begin{tabular}{|c|c|c|c|c|c|}
\hline \multicolumn{6}{|c|}{ Standard \#1: Foundations } \\
\hline No. & Items & Mean & SD & Rank & Level \\
\hline 9 & Impact of Labeling G/T individuals' & 2.49 & 0.61 & 1 & High \\
\hline 10 & $\begin{array}{l}\text { Rights \&responsibilities of students, parents, teachers \&other profession- } \\
\text { als, \&schools related to exceptional learning needs }\end{array}$ & 2.36 & 0.69 & 2 & High \\
\hline 5 & Issues in definition \&identification of $\mathrm{G} / \mathrm{T}$ individuals. & 2.30 & 0.72 & 3 & Moderate \\
\hline 11 & Issues \&trends in gifted education \&related fields. & 2.27 & 0.69 & 4 & Moderate \\
\hline 7 & Incidence \&prevalence of $\mathrm{G} / \mathrm{T}$ individuals. & 2.25 & 0.69 & 5 & Moderate \\
\hline 6 & $\begin{array}{l}\text { Relationship of gifted education to the organization \&function of educa- } \\
\text { tional agencies. }\end{array}$ & 2.21 & 0.72 & 6 & Moderate \\
\hline 3 & Laws \&policies related to education. & 2.16 & 0.74 & 7 & Moderate \\
\hline 4 & $\begin{array}{l}\text { Key issues and trends, including diversity and inclusion, connecting, } \\
\text { special , and gifted talented education }\end{array}$ & 2.13 & 0.75 & 8 & Moderate \\
\hline 1 & Historical foundations of $\mathrm{G} / \mathrm{T}$ education. & 2.11 & 0.74 & 9 & Moderate \\
\hline 2 & Models, theories ,\& philosophies that form the basis for G/T education & 2.11 & 0.75 & 9 & Moderate \\
\hline \multirow[t]{2}{*}{8} & $\begin{array}{l}\text { Issues, assurances \&due process rights related to assessment, eligibility, } \\
\& \text { placement within a continuum of services. }\end{array}$ & 2.08 & 0.75 & 11 & Moderate \\
\hline & Total Score & 2.22 & 0.57 & & Moderate \\
\hline
\end{tabular}

Table (2) illustrates that the degree to which the G/T teachers possess the concerned skills and knowledge was generally moderate; as the mean average was (2.22) and the SD (0.57). The paragraphs of this dimension ranged between the moderate and high degree; since the mean averages of such paragraphs varied between (2.49-2.08). Paragraph (9), "Identifying the Impact of Labeling Individuals G/T, came first with the mean average of (2.49) and
SD (0.61). Paragraph (10), "Identifying the Rights \& Duties of Students, Parents, Teachers, other Professionals and Schools Associated with Exceptional Learning Needs", came second with the mean average (2.36) and SD (0.69). Paragraph(2), "Identifying Philosophies, Theories, Models and Issues Associated with G/T Individuals, came in the next-to-last position with a mean average of (2.11) and SD (0.75). Paragraph (8), "Identifying the Issues and Rights 
Associated with the Evaluation, Aptitude, Referral and Constant Services", came last with a mean average of (2.08) and SD (0.75).

Table (3) illustrates that the degree to which the teachers of $\mathrm{G} / \mathrm{T}$ teachers possess the skills and knowledge in the "Development \&Characteristics of Learner" dimension was generally high; as the mean average was (2.43) and the SD (0.51). The paragraphs of this dimension ranged between the moderate and high degree; since the mean averages of such paragraphs varied between (2.66-1.94). Paragraph (6), "Identifying the Impact of Family upon the Development \&
Growth of G/T Individuals, came first with the mean average of (2.66) and SD (0.52). Paragraph (5), "Identifying the Intellectual (Mental, Academic, Leadership \& Technical) Characteristics of the G/T Individuals, came second with the mean average of (2.59) and SD (0.55). Paragraph (1), "Identifying the Natural \& Exceptional Growth Development Characteristics of the G/T Individuals, came in the next-to-last position with a mean average of (2.41) and SD (0.61). Paragraph (4), "Identifying the Impact of Medical Drugs \& Medicines upon the G/T Individuals, came last with a mean average of (1.94) and SD (0.83).

Table (3) The mean averages, SD's, rank and degree to which the G/T teachers possess the concerned skills and knowledge for the paragraphs of the " Development \&Characteristics of Learner " dimension are herein identified in descending order

\begin{tabular}{|c|c|c|c|c|c|}
\hline \multicolumn{6}{|c|}{ Standard \#2: Development \&Characteristics of Learner } \\
\hline No. & Items & Mean & $\mathrm{SD}$ & Rank & Level \\
\hline 6 & $\begin{array}{l}\text { Effects of families on the development of } \mathrm{G} / \mathrm{T} \text { individu- } \\
\text { als . }\end{array}$ & 2.66 & 0.52 & 1 & High \\
\hline 5 & $\begin{array}{l}\text { Cognitive characteristics of the G/T individuals in intel- } \\
\text { lectual ,academic, creative, leadership, \&artistic do- } \\
\text { mains. }\end{array}$ & 2.59 & 0.55 & 2 & High \\
\hline 2 & Similarities \&differences among the G/T individuals & 2.53 & 0.59 & 3 & High \\
\hline 3 & Educational implications of various gifts \& talents & 2.45 & 0.70 & 4 & High \\
\hline 1 & Typical \& atypical human growth \&development & 2.41 & 0.61 & 5 & High \\
\hline \multirow[t]{2}{*}{4} & $\begin{array}{l}\text { Effects of medications on individuals with gifts \& tal- } \\
\text { ents }\end{array}$ & 1.94 & 0.83 & 6 & Moderate \\
\hline & Total Score & 2.43 & 0.51 & & High \\
\hline
\end{tabular}

Table (4) The mean averages, SD's, rank and degree to which the G/T teachers possess the skills and knowledge for the paragraphs of the "Individual Learning Difference " dimension are herein identified in descending order

\begin{tabular}{|c|c|c|c|c|c|}
\hline \multicolumn{6}{|c|}{ Standard \#3: Individual Learning Difference } \\
\hline No. & Items & Mean & $\mathrm{SD}$ & Rank & Level \\
\hline 1 & Impact gifts \& talents can have on individual's life & 2.61 & 0.55 & 1 & High \\
\hline 6 & Differing learning styles of $\mathrm{G} / \mathrm{T}$ individuals. & 2.49 & 0.64 & 2 & High \\
\hline 5 & $\begin{array}{l}\text { Impact of learners' academic \& social abilities, attitudes, interests, \& } \\
\text { values on instruction \&career development. }\end{array}$ & 2.46 & 0.56 & 3 & High \\
\hline 2 & Academic characteristic of G/ $\mathrm{T}$ individuals \& disabilities. & 2.40 & 0.75 & 4 & High \\
\hline 3 & Affective characteristic of G/ T individuals\& disabilities. & 2.27 & 0.80 & 5 & Moderate \\
\hline \multirow[t]{2}{*}{4} & $\begin{array}{l}\text { Impact of multiple exceptionalities that may result in sensory, motor, } \\
\text { or learning needs. }\end{array}$ & 2.01 & 0.80 & 6 & Moderate \\
\hline & Total Score & 2.37 & 0.54 & & High \\
\hline
\end{tabular}

Table (5) The mean averages, SD's, rank and degree to which the G/T teachers possess the skills and knowledge for the paragraphs of the "Educational Strategies" dimension are herein identified in descending order

\begin{tabular}{|c|c|c|c|c|c|}
\hline \multicolumn{6}{|c|}{ Standard \#4: Instructional Strategies } \\
\hline No. & Items & Mean & SD & Rank & Level \\
\hline 4 & Use instructional time effectively & 2.69 & 0.55 & 1 & High \\
\hline 7 & Integrate social skills into curriculum & 2.57 & 0.57 & 2 & High \\
\hline 5 & $\begin{array}{l}\text { Teach individuals to use self-assessment, problem-solving, \& other cognitive strat- } \\
\text { egies to meet their needs. }\end{array}$ & 2.53 & 0.63 & 3 & High \\
\hline 3 & $\begin{array}{l}\text { Select, adapt, \&use instructional strategies \&materials according to characteristics } \\
\text { of G/T individuals. }\end{array}$ & 2.45 & 0.64 & 4 & High \\
\hline 6 & Choose \& use technologies to modify the instructional process. & 2.45 & 0.64 & 4 & High \\
\hline 8 & Use procedures to increase the individual's self- awareness. & 2.44 & 0.63 & 6 & High \\
\hline 2 & Technology for planning \&managing the teaching \&learning environment. & 2.39 & 0.74 & 7 & High \\
\hline \multirow[t]{2}{*}{1} & Sources of differentiated materials for $\mathrm{G} / \mathrm{T}$ individuals & 2.37 & 0.63 & 8 & High \\
\hline & Total Score & 2.49 & 0.51 & & High \\
\hline
\end{tabular}

Table (4) illustrates that the degree to which the G/T teachers possess the skills and knowledge in the "Individual Learning Difference " dimension was generally high; as the mean average was (2.37) and the SD (0.54). The paragraphs of this dimension ranged between the moderate and high degree; since the mean averages of such paragraphs varied between (2.61-2.01). Paragraph (1), "Identifying the Impact of Talent \& Excellence upon the Individuals' Lives", came first with the mean average of (2.61) and SD (0.55). Paragraph (6), "Identifying the Different Educational Mod- 
es of the G/T Students \& the Corresponding Instructional Strategies", came second with the mean average of (2.49) and SD (0.64). Paragraph (3), "Identifying the Characteristics of (G/ T) Students' \& those with Learning Difficulties", came in the next-to-last position with a mean average of (2.27) and SD (0.80). Paragraph (4), "Identifying the Impact of Various Disabilities that may Result from the Educational, Sensational \& Motor Needs", came last with a mean average of (2.01) and SD (0.80).

Table (5) illustrates that the degree to which the G/T teachers possess the skills and knowledge in the "Instructional Strategies" dimension was generally high; as the mean average was (2.49) and the SD (0.51). The para- graphs of this dimension were all high; since the mean averages of such paragraphs varied between (2.69-2.37). Paragraph (4), "Using Educational Time Efficiently", came first with the mean average of (2.69) and SD (0.55). Paragraph (7), "Activating the Social Skills through Curriculum", came second with the mean average (2.57) and SD (0.57). Paragraph (2), "Employing Technology in Planning, Education \& Securing the Suitable Educational Environment", came in the next-to-last position with a mean average of (2.39) and SD (0.74). Paragraph (1), "Identifying the Resources of the Different (G/T) Individuals' Tools", came last with a mean average of (2.37) and SD (0.63).

Table (6) The mean averages, SD's, rank and degree to which the G/T teachers possess the skills and knowledge for the paragraphs of the "Assessment" dimension are herein identified in descending order

\begin{tabular}{|c|c|c|c|c|c|}
\hline \multicolumn{6}{|c|}{ Standard \#5: Assessment } \\
\hline No. & Items & Mean & SD & Rank & Level \\
\hline 8 & Interpret information from formal \&informal assessment. & 2.52 & 0.56 & 1 & High \\
\hline 1 & Basic terminology used in assessment. & 2.50 & 0.61 & 2 & High \\
\hline 13 & Evaluate instruction 7 monitor progress for the $\mathrm{G} / \mathrm{T}$ individuals. & 2.48 & 0.59 & 3 & High \\
\hline 9 & $\begin{array}{l}\text { Develop \&administer nonbiased ,informal assessment proce- } \\
\text { dures. }\end{array}$ & 2.47 & 0.59 & 4 & High \\
\hline 16 & Create\& maintain records. & 2.46 & 0.58 & 5 & High \\
\hline 2 & $\begin{array}{l}\text { Legal provisions \&ethical principles regarding assessment of } \\
\text { individuals. }\end{array}$ & 2.44 & 0.66 & 6 & High \\
\hline 7 & Use formal \&informal assessments. & 2.44 & 0.61 & 6 & High \\
\hline 11 & $\begin{array}{l}\text { Identify supports needed for integration into various program } \\
\text { placements. }\end{array}$ & 2.44 & 0.59 & 6 & High \\
\hline 6 & Gather relevant background information. & 2.43 & 0.66 & 9 & High \\
\hline 15 & Evaluate learner products \&portfolios. & 2.42 & 0.57 & 10 & High \\
\hline 5 & Use \&limitations of assessment instruments for $\mathrm{G} / \mathrm{T}$ students. & 2.35 & 0.72 & 11 & High \\
\hline 12 & Develop or modify individualized assessment strategies. & 2.35 & 0.61 & 11 & High \\
\hline 17 & Use technology to control assessments. & 2.35 & 0.66 & 11 & High \\
\hline 10 & $\begin{array}{l}\text { Use assessment information in making eligibility, program, } \\
\text { placement decisions for } \mathrm{G} / \mathrm{T} \text { individuals. }\end{array}$ & 2.29 & 0.62 & 14 & Moderate \\
\hline 4 & $\begin{array}{l}\text { Screening, prereferral, referral, identification procedures for } \\
\text { G/T individuals. }\end{array}$ & 2.25 & 0.73 & 15 & Moderate \\
\hline 14 & $\begin{array}{l}\text { Use performance data \&information from all stakeholders to } \\
\text { make or suggest modifications in learning environments. }\end{array}$ & 2.23 & 0.57 & 16 & Moderate \\
\hline 3 & $\begin{array}{l}\text { National ,state or provincial \&local assess- } \\
\text { ment, accommodations modifications. }\end{array}$ & 2.16 & 0.66 & 17 & Moderate \\
\hline & Total Score & 2.39 & 0.49 & & High \\
\hline
\end{tabular}

Table (6) illustrates that the degree to which the G/T teachers possess the skills and knowledge in the "Assessment" dimension was generally high; as the mean average was (2.39) and the SD (0.49). The paragraphs of this dimension were between the high and moderate degree; since the mean averages of such paragraphs varied between (2.52-2.16). Paragraph (8), "the Ability to Deduce Data from Official \& Non-official Tests", came first with the mean average of (2.52) and SD (0.56). Paragraph (1), "Knowing the Concepts \&Terms Used in the Evaluation Process", came second with the mean average (2.50) and SD (0.61). Paragraph (14), "Using Performance-based Data $\&$ Data from the National Tests to carry out the Necessary Amendments on the Educational Environment", came in the next-to-last position with a mean average of (2.23) and SD (0.57). Paragraph (3), "Getting Acquainted with the International \& Local Tests, the Amendments \& the Ability to Harmonize them with the Culture to which the Individual under Evaluation Belongs", came last with a mean average of (2.16) and SD (0.66).

\section{Results Discussion}

In terms of the first question: what is the extent that the teachers of gifted and talented students have the skills and knowledge's accredited by the council of children with special needs? Means and standard deviations of "Foundations" dimension were intermediate while they were high for the other dimensions "Developmental \&Characteristics of Learners, Individual Learning Differences, Instructional Strategies, and Assessment". This is attributed to the attention of ministry of education in Jordan to prepare and train teachers of gifted and talented students in order to make them able to deal with all aspects related to the talented and 
gifted students by providing them with training programs before service-filed training-in schools and resource rooms related to gifted students, in addition to training during the services. This is consistent with the study of each of [3] as they recommended the necessity of training teachers preservice and during service because of its importance and benefit for the gifted students until all their needs are satisfied. It is consistent also with the study of [12] which showed that teachers who are trained on teaching the gifted students are more able compared with untrained teachers.

In the first dimension "Foundations", means were high in the skills of "Impact of Labeling individuals with gifts \& talents" and "Rights \&responsibilities of students, parents, teachers \& and other professionals\& schools related to exceptional learning needs", because the training received by the teachers of gifted is still need to take all aspects related to the issues of defining and identifying the gifted, laws and polices related to teaching the gifted ,and theoretical and philosophical basics on which gifted teaching is basedinto consideration.

This analysis is consistent with the study of [12] which emphasized on the importance that relevant teacher should be specialized in the field of the gifted to be able to teach this category of students.

The results of means related to the dimension of "Developmental \& Characteristics of Learners" were high on all items except the item that states that the knowledge of teachers of the effects of medical treatments and medicines on the gifted students whose means were intermediate because such teachers were not exposed to information, training experiences or enough information of its effects on the gifted students. This aspect is almost left to the family doctor or the school but not the teachers.

Furthermore, it is noted that results were high in terms of the item- knowing the cognitive characteristics (mental, academic, creative, leadership, and technical) of the gifted subjects. This is because of programs related to the preparation of the teachers of gifted students on knowing all the characteristics that distinguish the gifted students. This preparation of teacher has an effect on the manner in which they treat these students. This effect is considered positive because in case teachers possess knowledge about these characteristics, this would make them able to raise the level of stimulation and motivation and self-esteem among these students, and get the utmost of their potentials. This is consistent with the study of each: [22]; [1] ; [4].

The means of the dimension "Individual Learning Differences" were high in all questionnaire items except in the item related to the knowledge of the characteristics of the gifted subjects and those with learning difficulties among them, in addition to the item related to knowing the effects of multi- disabilities that can be resulted from the educational, sensual and motor needs. This is because there are significant (talented) students, but the suffer learning difficulty or disability because the issue of twice exceptional students is still new in Jordan .Before few years, university professors did not address the issue of twice exceptional students, but currently with new graduates, it is found that the concept of twice exceptional has become familiar by the teachers of the gifted. In this aspect, the importance of training during service is raised, so teachers of the gifted is focused on what they have missed, and what is taking place in terms of development in terms of information related to fields such as the issue of twice exceptional students. This is consistent with the study of both [3] as they focused on the importance of training during service for teachers of the gifted students.

For the dimension "Instructional Strategies", the means were high on all the items included in the dimension because the schools and resource rooms of the ministry of education and King Abdullah the $2^{\text {nd }}$ schools for Excellence subject teachers to best advanced educational programs such as enriching, acceleration and the advanced study courses along with focusing on the most important necessary educational strategies such as stimulating thinking, intuition and problem-solving, in addition to employing technology to improve educational methods, planning, education and provide the proper educational environment, and to know the resources of various tools of the gifted subjects which is consistent with he study of [4];[14]., [21].

The results of the "Assessment" dimension showed that the means of the teachers responses on its items were high in terms of teachers ability to explain the information from the formal and informal assessments, and know the concepts and terminology used in assessment and the ability to develop the informal evaluation procedures since teachers are trained on informal evaluation procedures, and methods and procedures in identifying and ways of application which is consistent with the study of [18] as both stressedin their study-the importance of training programs in helping students to evaluate the curriculum and design evaluation methods.

The study showed also that scores achieved in the item of knowing international and local tests and their amendments, and ability to adapt them to comply with culture of society to which the subject to be evaluated belongs-were intermediate .

The researcher attribute this finding to that many of the teachers of the gifted did not subject to advanced and specialized training courses in the legalized tests.

In addition, knowledge of tests is not among the conditions that should be available in the teachers of the gifted, and because the tests of the gifted need professionals who have enough experience in the filed of psychology, metrology and assessment.

\section{Recommendations}

Based on the study results, the researcher recommended to conduct more studies about competences required a among the teachers of gifted students, and on the remained dimensions stated in (CEC) which this study did not ad- 
dress including schools and leading centers that are not covered in this study in order to have more comprehensive and deeper image about the situation of competences of the teachers of gifted students in Jordan including all the governorates and far areas that lack specialized and qualified teachers to teach the gifted students, that should be in Arabic because of rare relevant resources. In addition teachers of gifted in Jordan should be provided with sufficient training on formal evaluation procedures, and the continuity of such training per-service and during services. In addition to creating academic programs of teachers of the gifted in all faculties of education in Jordan.

\section{References}

[1] Amois, N.,\& Shalkee, B.(1983).Needed Competencies for teaching Gifted Talented Student. British Journal of Education, 3(2), p 27.

[2] Baska, J., \&Johnson, S. (2007). Teacher Education Standards for the Field of Gifted Education, A Version of Coherence for Personal Preparation in the 21st Century. Gifted Child Quarterly , 51, 182-205.

[3] Carrington, N,. \& Bailey. (2000). How do pre-service teachers view gifted students? Evidence from a NSW Study Australasian Journal of Gifted Education ,9,1:18-22.

[4] Chan, D.W.(2001).Characteristics and competencies of teacher of gifted learners: the Hong Kong teacher perspective. Roper Review Agoura on gifted education vol.23, no.4 p197

[5] Cross \& Dobbs. (1987). Goals of a teacher training program for teachers of the gifted. Roeper Review , 9, 170-171.

[6] Davis,G., \&Rimm, S. (2004). Education of The Gifted $\&$ Talented (5 ed.). USA: Pearson.

[7] Donia, F., \& Micheal, J. (2004). Teacher of gifted student: suggested Multicultural characteristics and competences, gifted child quarterly .vol (42) NO3

[8] Easterl, K.S.(2001) .The state of elementary gifted and talented education in state of Texas, Thesis Ph.D. Sam Houston State University Includes Bibliographical references leaves 236-257.Vita.

[9] Feldhusen,J.F\& Hansen,J.(1988). Teachers of the Gifted:Prepration and Supervision. Gifted Education International , 5, 84-89.
[10] Feldhusen, J. (1997). Educating teachers for work with talented youth. In I. N. (Eds), Hand book of gifted education (pp. 541-555). Boston: Allyn\&Bacon.

[11] Firtz, J.J., Miller. H \&Kreutzer, J\& Macphee, D. (2000).Fostering Personal Teaching Efficacy Through Staff Development and Classroom Activities. Journal of Educational Research ,vol,88 , 200-208.

[12] Hansen, J.(1988). The relationships of skills and classroom climate of trained and untrained teachers of gifted students. Un published doctoral dissertation. Purdue University, W. Lafayette, Indiana.

[13] King Abdullah the 2nd Schools for Excellence.(2007). http://www.moe.gov.jo .Amman-Jordan.

[14] Kirk,S.,Gallagher,J.J.,Coleman,R.M.,\&Anastasiow,N.(2012 ).Educating Exceptional Children (13th . ed.).MA: Boston,Houghton Mifflin Company.

[15] Landrum, M . S., Callahan, C. M., \& Shaklee, B. D. (2003). Gifted program standards. Washington, DC: National Association for Gifted Children.

[16] Mills.C. (2003). Characteristics of Effective Teachers of Gifted Students:Teacher Background and Personality Styles of Students. Gifted Child Quarterly, 47, 272-281.

[17] Newland, T.E.(1962).Some observations on essential qualifications of teachers of mentally superior ,Exceptional children,29,111-114.

[18] Paryman,L., \&Mosha,S. (1990).Addressing the perceive needs of Regular classroom Teacher in teaching the Gifted student. British Journal of Education .vol. 12. no2.p(19-26)

[19] Renzulli, J.(1981) Identifying Key Features in Programs for the Gifted. In I. (Eds.), Psychology \&Education of the Giifted (3 ed., pp. 214-219). New York: Irrington.

[20] Sharma.S. (2006). Education of the Gifted:. India: Shipra Publications.

[21] Shaunessy, E. (2005). Assessing and addressing teacher's attitudes toward information technology in the gifted classroom, Gifted Child Today, 28 (3), 45-53.

[22] Silverman, L.K.(1980).How are gifted teachers different from other teachers ?Paper presented at the annual convention of the National Association for Gifted Children, MN: Minneapolis. 